\title{
MILITAIRE GAME(R)S: VECHTEN IN DE VIRTUELE WERKELIJKHEID
}

De wereld is in constante staat van oorlog. Honderdduizenden soldaten zijn elk moment van de dag bezig met het uitvechten van vluchtige digitale conflicten op gesimuleerde slagvelden. Deze virtuele oorlogsvoering omvat niet alleen grote groepen adolescenten, maar ook de leden van verschillende krijgsmachten gebruiken technologisch geavanceerde digitale computer-games. Het aloude credo 'ter lering ende vermaeck' is buitengewoon van toepassing op militaire games. PC-spellen uit het populaire First-Person Shooter-genre bieden een interessant uitgangspunt om de relatie tussen de representatie van recente militaire conflicten, en dan met name de Amerikaanse War on Terror, en populaire cultuur uit te diepen. Een First-Person Shooter (F PS) is een game waarbij een speler vanuit een eerstepersoonsperspectief door een driedimensionale virtuele wereld kan navigeren. Spelers kunnen daarbij interacteren met de omgeving en maken vaak gebruik van een groot arsenaal aan wapens om een missie of doel te behalen. Fps-games variëren wat betreft thematiek en complexiteit en kunnen alleen gespeeld worden (singleplayer), met meerdere mensen tegelijk (co-op) of met meerdere mensen tegelijk tegen elkaar (multiplayer), vaak via internet. Dezelfde spellen die door het Amerikaanse leger worden gebruikt om soldaten klaar te stomen voor lopende en komende conflicten worden door gamers gebruikt in de strijd tegen verveling. Het adagium 'there's only one truth about war: people die', wordt door F Ps-games, maar ook tijdens de representatie van oorlog in het journalistieke discours, regelmatig zwaar op de proef gesteld. Het volgende potje begint alweer, het is tijd voor actie of zoals spelers elkaar toeschreeuwen in de FPS AMERICA's ARMY: 'Open Fire!'

\section{Belang en beeldvorming}

De invloedrijke theoreticus Espen Aarseth meent dat games misschien wel het belangrijkste product zijn van computertechnologie, zeker gezien in een culturele context. ${ }^{\mathrm{I}}$ Nagenoeg alle elementen van de wijd en zijd verspreide en groeiende cybercultuur komen terug in deze nieuwe vorm van digitaal vermaak. 
Fenomenen als het bouwen van duurzame virtuele communities, het aannemen van een andere (online) identiteit en vragen met betrekking tot toegang tot nieuwe media komen allemaal terug in games. Veel wetenschappers binnen het opkomende wetenschapsgebied van game studies laten geen mogelijkheid onbenut om de maatschappelijke relevantie van games en game cultuur te benadrukken. Niet alleen groeit de computerspellenindustrie in economisch opzicht op indrukwekkende wijze, games nemen ook een steeds belangrijkere plek in binnen de populaire cultuur en het leven van vele jongeren over de hele wereld.

De sinds het midden van de negentiende eeuw gevormde relatie tussen publieke opinie, media, (internationale) politiek en beeldvorming, zoals vanuit verschillende perspectieven wordt belicht in de inleiding van het themanummer 'Media \& Oorlog' van het Tijdschrift voor Mediageschiedenis (I999, 2) is nog immer actueel. ${ }^{2}$ Hiermee wordt de kritiek verworpen dat media geen geschiedenis van belang zouden voortbrengen en 'slechts exponenten zijn van een per definitie vluchtige en dus te verwaarlozen populaire cultuur'. ${ }^{3}$ Juist de bestudering van populaire cultuur en de interactie met de representatie van recente conflicten in nieuwe media, vormt de kern van dit essay. Patrick Crogan, beïnvloed en geïnspireerd door denkers als Manuel De Landa, Paul Virilio en Friedrich Kittler, gebruikt het volgende syllogisme om de relatie tussen games en de representatie van oorlog aan te geven. ${ }^{4}$ Ten eerste zijn de menselijke cultuur en beschaving altijd onlosmakelijk verbonden geweest met de krijgsmacht en de oorlogsindustrie. Daarnaast zijn computerspellen onderdeel van de menselijke cultuur, technologie en beschaving. Dus games zijn een waardevolle manier om de relatie tussen oorlogs- en vredessituaties, technologie en civilisatie te problematiseren.

\section{Van representatie naar simulatie}

Waar televisiejournaals een militair conflict enkel representeren, daar zijn F PS-games interactieve media die zowel representeren als simuleren. Ludoloog Gonzalo Frasca maakt het verschil tussen representeren en simuleren inzichtelijk en betoogt dat simulatie de basiseigenschap is van videogames. ${ }^{5}$ Het belangrijkste ontologische verschil tussen games - te zien als op regels gebaseerde constructen - en bewegende beelden zoals film en televisie, is dat games niet slechts zijn gebaseerd op representatie maar primair gebruik maken van simulatie door het gedrag van verschillende objecten en systemen te modelleren. ${ }^{6}$ Dit staat in tegenspraak tot bijvoorbeeld films, die zijn op te vatten als texten die primair gebaseerd zijn op representatie en narratie. Frasca merkt op dat representatie altijd een incomplete aangelegenheid is. Dit geldt echter door het inherent simplificerende karakter van modellering evenzeer voor simulaties. Simulatie-ontwikkelaar Chris Crawford wijst op de ogenschijnlijke kracht van simulaties.? 
Door het aura van digitale precisie worden simulaties gezien als producten van calculatie in plaats van expressie, terwijl, zo betoogt Crawford terecht, simulaties samenstellingen zijn van subjectieve algoritmes. Het simuleren van absolute objectiviteit is ook door middel van computersimulaties onmogelijk. Simulaties zijn altijd benaderingen die keuzes forceren, keuzes die enige vorm van subjectiviteit met zich meebrengen. Simulaties kunnen spelers het gevoel geven in staat te zijn om te ervaren hoe het is om 'echt' oorlog te voeren.

Virilio meent dat 'despite the massive

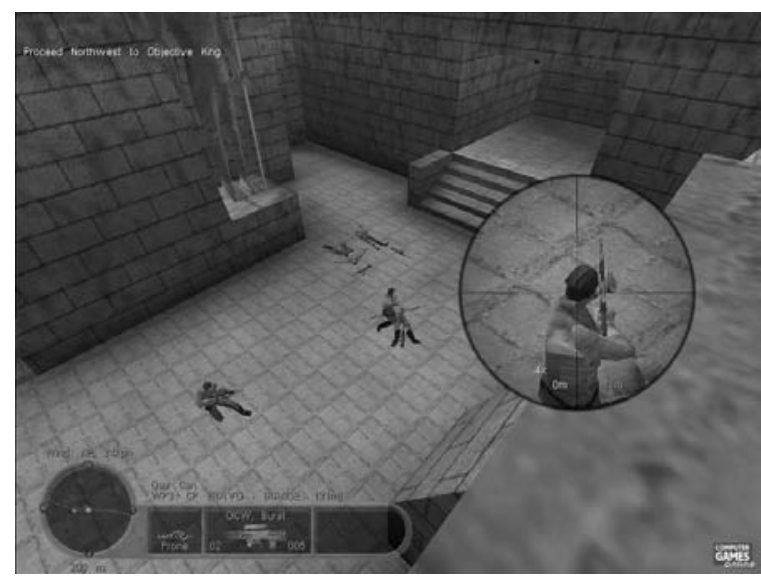

Het gezichtspunt van een sniper in de FPS DELTA FORCE: LAND WARRIOR (Nova Logic, 2000) accumulation of documents, publicity and films, young army recruits still say in response to questions that they cannot imagine what a war would be like. ${ }^{8}$ Dit gebrek aan voorstellingsvermogen wordt, mede door de de-realisatie van moderne oorlogsvoering, door F PS-games doorbroken. Jason Amerine, kapitein in het Amerikaanse leger tijdens de Tweede Golfoorlog, ziet F P s-spellen als overtuigende simulaties:

“"It was kind of funny, because it was sort of like. Well, this is just like what I did on my computer, I guess.” Having reenacted similar scenarios so many times, [Amerine] found these games had helped prepare him for that moment, when he came up firing. "It definitely made it easier ... in a lot of ways it was similar to what you would see if you were playing a sniper in the original DELTA FORCE, for example.",9

Televisiejournaals schotelen de werkelijkheid voor door middel van zorgvuldig gekozen beelden. Gamers zijn echter in staat om binnen de grenzen van het spel hun eigen werkelijkheid te construeren. De receptie van een journaal maakt een actieve lezing van een televisieprogramma mogelijk, maar het daadwerkelijk actief participeren in de representatie kan tot op heden niet. Het actief participeren in een computerspel zegt overigens niets over de lezing van deze game. Zoals Crawford betoogt, hebben computerspellen een aura van objectiviteit waardoor gamers het gevoel kunnen hebben te ervaren hoe 'het echt is om oorlog te voeren. $^{\text {,Io }}$

Voor een analyse tussen F PS's en de representatie en simulatie van recente conflicten is de bestudering van het F PS-genre van belang voor de verdere bestudering van de rol die FPs's hebben binnen de hedendaagse populaire cultuur, omdat veel technologische en sociale conventies zijn gevormd tijdens de ontwikkeling van het genre. 


\section{First-Person Shooter geschiedenis}

De wordingsgeschiedenis van de verzameling computerspellen die al snel bekend zou worden als First-Person Shooter games, laat zich lezen als een jongensboek. In het boek Masters of Doom: How Two Guys Created an Empire and Transformed Pop Culture, vertelt David Kushner het verhaal van de twee makers van de eerste succesvolle F P S-games, John Carmack en John Romero, oprichters van id Software. ${ }^{\text {II }}$ Beide jongens hebben door de ontwikkeling van hun games een nieuw tijdperk ingeluid in de ontwikkeling van digitale spellen en daarmee populaire cultuur voor altijd veranderd. Een ietwat deterministische claim die de nodige kritiek opgeroepen heeft. Zo meent journalist James Wagner Au dat de ontwikkelaars van id Software te veel krediet krijgen voor spellen die bewust niet het volle potentieel van het medium benutten door te kiezen voor snelle actie en geweld in plaats van het toevoegen van meer tactische elementen. ${ }^{\text {I2 }}$ Een van de basiselementen van alle (digitale) spellen is conflict, op een eenvoudige manier te representeren en simuleren door gewelddadige thema's. Game designers Katie Salen en Eric Zimmerman menen dat conflict zelfs een centraal element is in elk spel. ${ }^{\mathrm{I}}$

Met WolfENSTEIN 3D introduceerde id Software in I992 een spel met aanzienlijke technische noviteiten maar ook met een gewelddadig karakter. Gamers konden vanuit het perspectief van een Amerikaanse soldaat door driedimensionale ruimtes rennen, verbonden door deuren en gangen. Deze ruimtes waren bevolkt door allerlei Duitse stereotypes uit de Tweede Wereldoorlog, het meest gerepresenteerde moderne conflict in F PS-spellen. Andere voorbeelden zijn de MEDAL OF HONOUR serie (2OI5 Inc, 2002), BATTLEFIELD I942 (Digital Illusions CE, 2002) en CALl OF DUTY (Infinity Ward, 2003). Dat de eerste echte F P Sgame WOLFENSTEIN 3D aan dit succes heeft bijgedragen, lijkt overduidelijk.

Al vrij snel na wolfenste I 3 D kwam Doom (I993) uit, misschien wel de bekendste FPS ooit. Dit spel, in economisch en technologisch opzicht een enorm succes, werkte het gewelddadige thema van wO LF E NSTE IN 3D verder uit en kwam met nieuwe technische innovaties. Doom had een nog sneller tempo en simuleerde de dood gedetailleerder dan alle andere spellen ooit gedaan hadden, met grotere wapens en vooral meer bloed en gore. Het plot van Dоо $\mathrm{M}$ is in enkele regels samen te vatten en dient slechts als excuus voor bepaalde keuzes in het ontwerp. In роом is de speler een naamloze space marine die op een militaire basis op Mars geheel alleen overgeleverd is aan hordes gemuteerde beesten die met een groot arsenaal aan wapens afgeschoten dienen te worden, met als enig doel: overleven. De makers van роом hadden een uitgesproken voorkeur voor een subcultuur die duidelijk zijn sporen heeft nagelaten in het ontwerp van hun spellen. De voorliefde van het ontwikkelingsteam voor horror- en zombiefilms heeft onmiskenbaar een stempel gedrukt op de eerste FPS-games en de F P S-discourse. FPs-termen als deatmatch en respawning zijn ontstaan tijdens de eerste dagen van Dоом. ${ }^{\mathrm{I}}{ }^{4}$ Veel FPs-spellen hebben voortgeborduurd op de 
gewelddadige thematiek en ontwerpconventies van Doom en Dоом 2. De FPs-game PAinkiller (People Can Fly, 2004) is een voorbeeld van een geavanceerde versie van Dоом met hetzelfde level-design en dezelfde nadruk op wapens en zombies. ${ }^{\text {I5 }}$

Behalve enkele technische innovaties op esthetisch gebied, zoals het gebruik van licht en schaduw, voegde Dоoм een zeer belangrijk element toe aan de steeds groter wordende game-cultuur, namelijk het implementeren van netwerktechnologie. Was WOLFENSTEIN

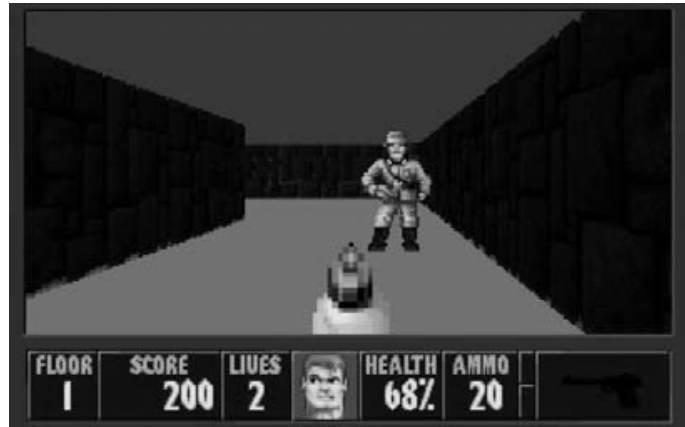

Ingame screenshot uit de FPS WOLFENSTEIN 3D (id Software, 1992) 3D nog een singleplayer game, Doom maakte het mogelijk samen te werken met vrienden, om zo het massale aantal vijanden samen te lijf te gaan. Het tegen en met elkaar spelen via een netwerk bleek het ei van Columbus te zijn. De solitaire aangelegenheid van het spelen van F Ps-spellen veranderde in een sociaal interactief tijdverdrijf met gelijkgestemden. ${ }^{16}$ F P sgamers steken veel tijd in hun hobby. Het uitspelen van een singleplayer-deel van een F PS-game kan vijftien tot meer dan veertig uur duren en door het onvoorspelbare en sociale karakter van multiplayer spellen is het niet ongewoon dat gamers meer dan honderd of tweehonderd uur met hetzelfde spel bezig zijn, soms zelfs met dezelfde map. Dit staat in schril contrast met de tijd die gemoeid is met bijvoorbeeld het bekijken van films. Daarbij stopt het voor een groot deel van de gamers niet bij het spelen van hun favoriete spel. Vaak wordt er geen moment onbenut gelaten om tijdens het spelen opgedane sociale contacten in stand te houden, te participeren in online discussies of het fabriceren van aan games gerelateerde websites, posters, filmpjes en muziek. ${ }^{{ }^{7}}$

De ontwikkeling van Dо o $\mathrm{m}$ betekende niet alleen een revolutie voor computerspellen op de PC, maar ook de geboorte van een hele nieuwe cultuur, namelijk de mod (modificatie) cultuur. Mede dankzij de open source ethos van de belangrijkste techneut in het ontwikkelingsteam van id Software, John Carmack, zijn noties over het denken over intellectual property (IP) en het modificeren van (nieuwe) media, in dit geval games, blijvend veranderd. ${ }^{\mathrm{I} 8}$ Mods zijn software aanpassingen aan bestaande spellen, variërend in grootte en complexiteit, gemaakt voor en door gamers. Voor het spelen van een mod is altijd het originele (commerciële) spel nodig. Zo dient een speler het spel BATTLE F I E LD I942 (Digital Illusions CE, 2002) in bezit te hebben als hij de mod DESERT COM BAT (Trauma Studios, 2003) wil spelen. Mods worden voornamelijk gratis via het internet gedistribueerd. Gebruik makend van vrij beschikbare software dragen gamers bij aan de innovatie en (co-)productie van F PS-games. Een minderheid van de spelers is op deze manier nog actiever met de spellen bezig, waardoor de grens tussen speler en auteur vervaagt. Het bottum-up karakter van de modcultuur zorgt voor oorspronkelijk materiaal. Doordat er geen markt bedient 
hoeft te worden, kunnen ontwikkelaars van mods vrijelijk experimenteren met nieuwe spelconcepten en controversiële inhoud. Waar de technologisch innovatieve maar inhoudelijk conservatieve computerspellenindustrie terughoudend is in het testen van nieuwe inhoud of simpelweg de creativiteit mist om dergelijk materiaal te produceren, daar experimenteren modders erop los, met wisselend succes. De enorme creatieve kracht die er van de F P S-mod-cultuur uitgaat, is niet voorbijgegaan aan het Amerikaanse leger, die manieren zoekt om het potentieel van de mod-cultuur aan te wenden in het belang van de (defensie-) industrie. ${ }^{\text {I9 }}$ Ook op het gebied van het vormen van een culturele infrastructuur, dat wil zeggen zelfvormende en instandhoudende game communities, kan het leger veel leren, menen J.C. Herz en Michael R. Macedonia. Beiden zijn in dienst van het Amerikaanse leger waarbij Macedonia hoofd is van het technische departement van STRICOM (Simulation Training and Instrumentation Command), daarbij verantwoordelijk voor het gebruik van games en simulaties binnen het Amerikaanse leger. Zij stellen de volgende relevante, maar nog niet te beantwoorden vraag met betrekking tot de game-cultuur: 'The question is whether the military will harness those dynamics to transform itself, or whether this generation of soldiers will transform the military, over a longer period of time, despite itself.

\section{De tactical shooter en de oorlog tegen terreur}

Het F P S-genre sloeg een nieuwe weg in aan het einde van de vorige eeuw, waardoor het genre nog interessanter werd voor militaire strijdkrachten die gebruik wilden maken van commerciële simulatietechnologieën voor trainingsdoeleinden. In I999 werd Co U NTER-STRI KE ontwikkeld, een mod gebaseerd op de F P S HALF-LI F E (Valve, I998). Het spel begon als een 'simpele' modificatie, niet ontwikkeld door een grote game ontwikkelaar maar door een jonge Amerikaan, Minh 'Gooseman' Le. ${ }^{20}$ CoU NTER-STR I KE is een online multiplayer spel waarin twee teams, de terrorists en de counter-terrorists tegen elkaar strijden in relatief realistische scenario's. CoU NTER-STR I KE voegde een belangrijk gameplay-element toe aan het FPs-genre, namelijk tactiek. Doordat spelers in teamverband een doel hebben, zoals het plaatsen van een bom of juist het verhinderen hiervan, dwingt de gameplay van COUNTER-STRIKE gamers in een bepaalde mate samen te werken. Spelers hebben slechts één leven en mogen pas weer meespelen als een volgende sessie begint. Hierdoor wordt het virtuele leven voor een speler, en dus voor het team, waardevol. Waar eerdere F PS-games nog hersenloze schietspellen waren, zorgde COUNTER-STRI KE ervoor dat gamers zich verenigden in tijdelijk of permanent teamverband.

Het FPS-genre is verder uitgediept door een groot aantal tactische FPSgames, waarbij met name de nadruk is gelegd op de zo realistisch mogelijke weergave van gewapende conflicten. Daarnaast is er, parallel aan deze verdie- 
ping, een groot aantal F Ps-spellen met de War on Terror als thematiek, al dan niet passend binnen het tactical f ps-genre. Tactical F Ps-games hebben voornamelijk een (para)militair karakter. Er bestaat een grote reeks commerciële spellen zoals de DeLTA ForCe serie, van uitgever NovaLogic, TOM CLANCY's RAIN BOW 6 serie (Red Storm Entertainment), OPERATIO N FLASH PO INT: COLD WAR CRISIS (Bohemia Interactive, 200I) en SOLDNER: SECRET WARS (Wings Simulations $\mathrm{GmbH}$, 2004). Ook is er een groot aantal tactical Fps-mods die dagelijks door duizenden online gespeeld worden.

Er is een onmiskenbare wisselwerking tussen de thematiek van FPS-games en mods en de representatie van recente conflicten in deze games en andere (nieuws) media. Ontwikkelaars van F P s-spellen en modificaties zijn, in vergelijking met TV-series en (Hollywood) films, niet bang om direct te refereren aan recente (Amerikaanse) militaire conflicten, zoals de Eerste en Tweede Golfoorlog, Operatie Restore Hope in Somalië, Operatie Enduring Freedom in Afghanistan en de voortdurende War on Terror die uitgevochten wordt over de gehele wereld. In 2002 werd CON FLICT: DESERT STORM (Pivotal Games) uitgebracht en kort na het begin van de Tweede Golfoorlog verscheen CONFLICT: DESERT Storm i - вACк to вAG hdad (Pivotal Games, 2003) in de schappen. In deze twee games kunnen spelers het als Brit of Amerikaan opnemen tegen grote groepen Irakezen. Losjes gebaseerd op het boek Black Hawk Down is de FPS DELTA FORCE: BLACK HAWK DOWN (Novalogic, 2003) waarin het gevecht tussen US Special Forces en Somalische milities gesimuleerd wordt. ${ }^{2 \mathrm{~T}}$ Een F Ps die beide Golfoorlogen simuleert is DESERT COM вAт (Trauma Studios, 2003). In deze geavanceerde modificatie kunnen spelers in de virtuele huid kruipen van zowel Amerikanen als Irakezen en gebruik maken van het wapentuig van beide strijdmachten, zoals helikopters, tanks en straaljagers. Binnen de mod is een groot aantal maps beschikbaar die verwijzen naar plekken waar gevochten is in beide oorlogen, zoals Khafji Docks, Bashrahs Edge, en de grote tankslag aan het begin van de Eerste Golfoorlog, The Battle of 73 Eastings. Des e RT com вat heeft een grote schare fans die het spel gebruiken om posters en filmpjes te maken met de Golfoorlog als middelpunt.

Het conflict in het Midden-Oosten wordt niet alleen gesimuleerd door F PSgames ontwikkeld door Amerikanen en Europeanen. Zo geeft UNDERASH (Supersoft, 2002) Arabisch sprekende spelers de kans om een Palestijnse jongen te spelen die het tijdens de eerste Intifada van I988 tot I992 opneemt tegen Israëlische soldaten en kolonisten. De opvolger van UNDERASH, UNDER SIEGE, zal eind 2004 uitkomen en is gericht op een internationaler publiek. ${ }^{22}$ De FPS SPECIAL FORCE (2003) is ontwikkeld door het Hizbullah Central Internet Bureau en heeft daarmee een meer politiek karakter. Het doel van het spel is om de Israëlische premier Sharon te elimineren terwijl de speler leert over: 'the history of what really happened in the south of Lebanon ... and deliver a message that man should defend his country and land against the usurpers and occupiers. $^{23}$ 


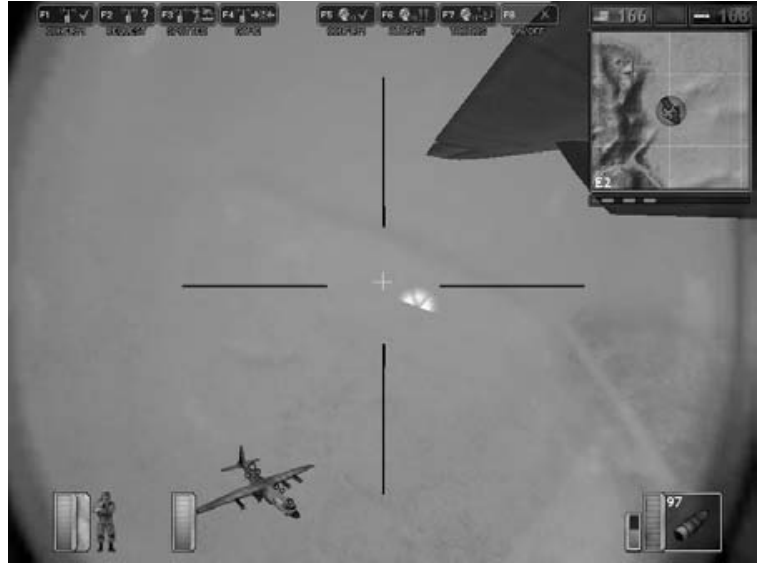

Ingame screenshot uit de FPS mod DESERT COMBAT, gemaakt vanuit een AC-130 gunship (Trauma Studios, 2003)
Door de verregaande vertechnologisering van de Amerikaanse strijdmachten en hun toe-eigening van commerciële technieken voor simulatie, heeft moderne oorlogsvoering veel weg van het spelen van computergames. In het veld van (computer) simulatie is te zien hoe media de relatie structureren tussen de kijker en de wereld. ${ }^{24}$ Voor soldaten worden moderne conflicten gemediëerd door dezelfde technologieën als die van de populaire cultuur. Het volgende citaat uit een Amerikaans online tijdschrift vat deze ontwikkeling als volgt samen:

'Most of the means of human perception in modern vehicles of war are already electronically mediated. In Desert Storm, both air pilots and tank crews spent much of their time in combat watching infrared targeting scopes. Much the same goes for Patriot missile crews, Aegis cruisers, AWACs radar personnel, and so on. War has become a phenomenon that America witnesses through screens. ${ }^{25}$

Het publiek ervoer de strijd tegen Saddam Hoessein op soortgelijke wijze. Operatie Desert Storm werd een conflict waarin alleen die beelden werden getoond 'waarvan de newsmanagers in het coalitiekamp meenden dat het geen gevaar opleverde voor het moreel van de eigen troepen en vooral van het eigen thuisfront' met als gevolg dat de media 'noch in de aanloop naar de strijd noch tijdens de oorlog zelf, in staat waren invloed van betekenis uit toe oefenen.' Hierbij wordt invloed gedefinieerd als het effect van de journalistiek op het internationale vredes- en veiligheidsbeleid. In een tijd dat Hollywood zijn vingers niet durfde te branden aan films over operatie Desert Storm, bleek met name de modcultuur te voorzien in de blijkbaar aanwezige vraag naar de representatie maar bovenal simulatie van het conflict van I99I.

\section{AMERICA'S ARMY: An army of gamers}

Een FPs-game die haast een logisch gevolg is van de ontwikkelingen binnen het genre, die een uitwerking is van het F PS-subgenre van de tactical shooters en die de simulatie van oorlogsvoering een stap verder voert, is AMERICA'S ARMY: SPECIAL FORCES. ${ }^{26}$ Dit PC-spel, speelbaar onder Windows, Mac os en Linux, is ontwikkeld door het Amerikaanse leger. De eerste versie werd uitgegeven op 
4 juli 2002. AM ERICA's ARMY is, zeker in de ogen van veel gamers, boven alles 'just a game', één van de vele spellen op de drukbevolkte F Ps-markt. Het spel is gratis, maar ook dat is niet uniek. Het door commerciële ontwikkelaars uitgegeven Wolf en STein: en EMY TER Ritory (Mad Doc Software en Splash Damage, 2003) is eveneens gratis online te verkrijgen en te spelen. Wat AM E RICA's ARMY echter enig in zijn soort maakt, is de aanwezigheid van vier interacterende dimensies: die van advergame, edugame, propagame en test tool. ${ }^{27}$ Sommige van deze dimensies zijn apart terug te vinden in andere F PS-spellen, maar juist de aanwezigheid van deze vier maakt AMERICA's ARMY uniek.

AMERICA'S ARMY is in eerste instantie bedoeld om rekruten te werven voor de US Army en is in die hoedanigheid te zien als een advergame. Advergames zijn vaak kleine simpele computerspellen op de websites van bedrijven waarin reclameboodschappen geïntegreerd zijn. AM E R ICA's A R MY valt echter op wat betreft omvang en complexiteit, maar ook vanwege het feit dat het geen gegevens verzamelt van spelers. Het spel tracht slechts gamers te informeren over bepaalde aspecten van het leger alsmede hen bloot te stellen aan legersymbolen, logo's en slogans. Het Amerikaanse leger, dat geen dienstplicht kent, geeft jaarlijks twee miljard dollar uit om nieuwe soldaten te werven en een van zijn middelen is de website www.goarmy.com. Op deze website is een schat aan informatie te vinden over de verschillende carrièremogelijkheden in het leger. Naast banners, advertenties in tijdschriften, het sponsoren van een raceteam en het bezoeken van scholen door professionele recruiters, zet het leger AMERICA'S ARMY in om bezoekers te genereren voor de spil in de rekruteringscampagne, de GoArmy website.

Een dimensie die logischerwijs voortvloeit uit het doel van het leger om gamers te informeren over de mogelijkheden die het leger biedt, is de edugamedimensie. Gamers worden direct en indirect blootgesteld aan allerlei informatie en rituelen van het Amerikaanse leger. Direct gebeurt dit door middel van het volgen van (verplichte) trainingen waarin de zogenaamde core values van het leger gerepresenteerd en gesimuleerd worden, zoals het volgen van een virtuele basic training. Indirect wordt door middel van verschillende spelmechanieken getoond welke rollen soldaten kunnen hebben, hoe iemand met een shock te behandelen en dat het schieten op eigen soldaten of burgers onmiddellijk afgestraft wordt. Een andere kant van de edugame dimensie is het feitelijke gebruik van AMERICA's ARMY als trainingsmiddel binnen het Amerikaanse leger. Zo wordt het spel gebruikt als voorbeeld binnen diverse trainingsprogramma's. Infanteriesoldaten gelegerd in Fort Benning gebruiken het spel voor er daadwerkelijk een voet op de oefenbaan wordt gezet en eerstejaars kadetten aan West Point gebruiken het spel om landnavigatie te trainen.

De derde dimensie behelst het gebruik van AMERICA's ARMY als test tool, oftewel testmiddel. Het gebruik van simulaties voor trainingsdoelen binnen de Amerikaanse strijdmachten blijft toenemen en binnen het ontwikkelingsteam is een aparte groep die zich bezighoudt met het (door)ontwikkelen van 
Een speler die Basic Training doorloopt en zich aan het kwalificeren is op de rifle-range. Ingame screenshot uit de FPS AMERICA's ARMY (Dept. of Defense, US Army, 2002)

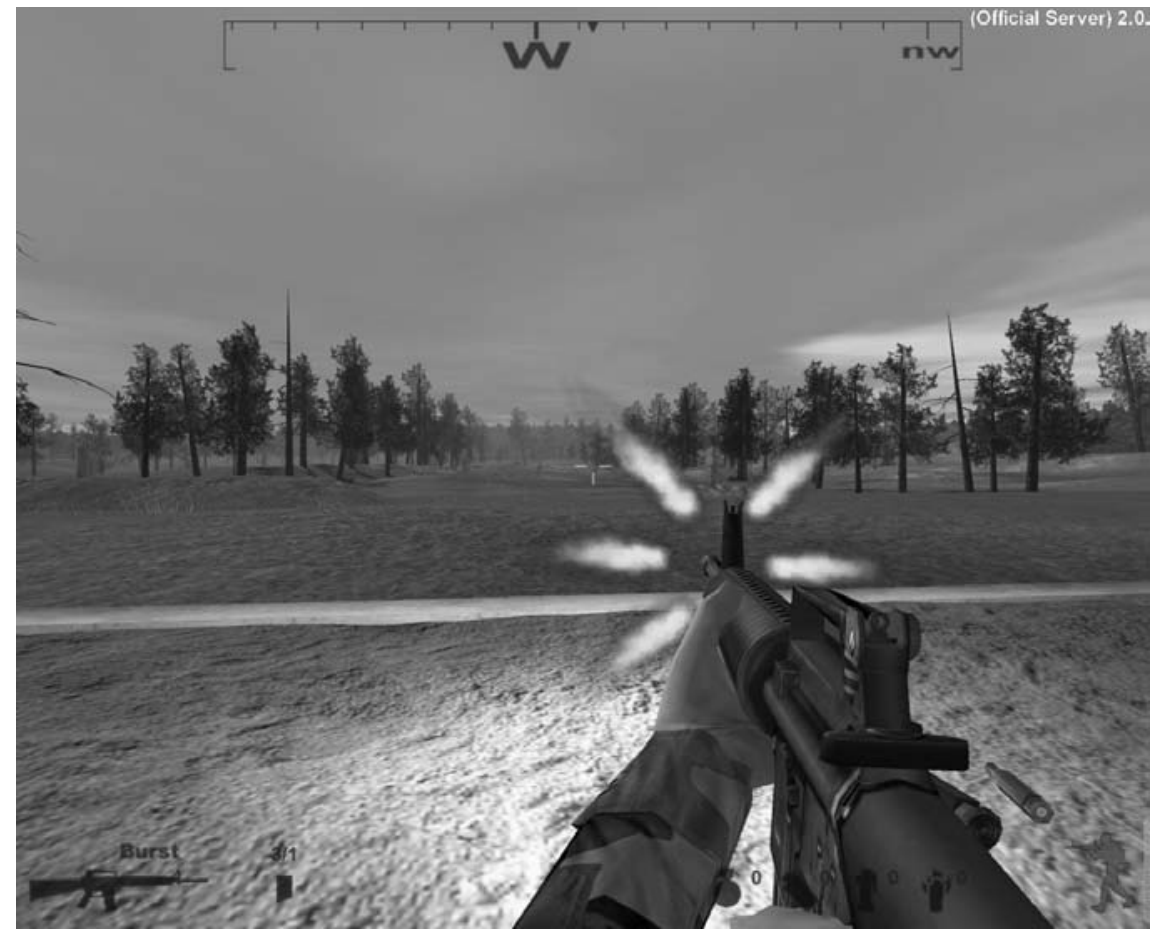

spelonderdelen om met name nieuwe wapens en uitrusting te testen, zoals de op afstand bestuurbare Talon Robot die gebruikt wordt om mijnen onklaar te maken. De ontwikkelaars, opererend onder de naam 'Army Game Project' (AGP), doen allerminst geheimzinnig over deze kant van het spel. Een aantal nieuwe wapens, dat nog niet in massaproductie is genomen, zal in de komende versies van het spel te gebruiken zijn, in het geval van de publieke versie om ze virtueel te testen en in de legerversie om soldaten te trainen in het gebruik.

Het vierde aspect, AM ERICA's ARMY als propagame, is wellicht de meest controversiële dimensie. De propagame dimensie heeft vooral betrekking op de representatie van de normen en waarden van het Amerikaanse leger en de plek die het Amerikaanse leger binnen de Amerikaanse maatschappij inneemt. AMERICA'S ARMY is ontegenzeggelijk een ideologisch construct en in lijn met de ideeën van zowel Frasca als Crawford schotelt AM E RICA's ARMY een subjectief beeld voor van het Amerikaanse leger in het algemeen en infanteriegevechten in het bijzonder. Het volgende citaat van C. Chambers, adjunct-directeur van het AG P, is sprekend: 'We think the game reflects positively on the American way of fighting a war. That's why we don't mind that 25 percent of our audience is overseas. ${ }^{28}$ Frasca gebruikt het volgende voorbeeld om de subjectiviteit in het ontwerp van simulaties te omschrijven: 
'There is an essential difference between creating a simulated environment where it is just possible to murder people, and another where you get a reward (score, extra levels) for doing it. ${ }^{29}$

Hoewel de ontwikkelaars aan de ene kant benadrukken dat het mogelijk is om een online sessie te winnen zonder nodeloos geweld te gebruiken, is het gebruik van dodelijk geweld vereist to defend freedom. ${ }^{30}$ Een paradoxaal uitgangspunt: het grootste deel van de AM E R ICA'S ARMY-spelers zal beamen dat juist het aangaan van vuurgevechten of het afwachten tot een tegenspeler voorbij komt om hem vervolgens te elimineren, voor de grootste spelvreugde zorgt. Iets waarin AMERICA'S AR MY overigens allerminst verschilt van andere F PS-games. Hoe geavanceerd en gecontroleerd AMERICA'S ARMY ook is, het blijft een First-Person Shooter spel.

Een succesvolle start

AMERICA'S ARMY is een overdonderend succes voor het Amerikaanse leger in economisch, sociaal en technologisch opzicht. Zo is het spel zeer kosteneffectief. De zeven miljoen opstartkosten en twee tot drie miljoen dollar per jaar aan onderhoudskosten, zijn maar een fractie van het jaarlijkse budget van twee miljard dollar dat uitgegeven wordt om nieuwe rekruten te werven. ${ }^{3 \mathrm{I}}$ Vergeleken met televisiecommercials, advertenties in kranten en magazines of het maken van een (promotie-)film, is AMERICA'S ARMY financieel gezien efficiënt en effectief. Fps-spellen en game communities hebben een sociaal karakter. Ze dragen er (onbewust) zorg voor dat de boodschap en informatie over AM E RICA'S AR MY, maar ook het spel zelf, kosteloos wordt verspreid - een proces dat ook wel viral marketing wordt genoemd. Sinds 2002 hebben 2.I miljoen spelers hun basic training afgemaakt en zijn dus in staat om online te spelen. Met dit aantal staat AMERICA's ARMY dan ook in de top vijf van meest gespeelde online F P s-games. Elk moment van de dag zijn er tussen de drieduizend en vijfduizend spelers online. ${ }^{32}$ Het grootste deel van de spelers komt uit Amerika maar ook Nederland en Duitsland leveren relatief veel spelers. Er wordt veel tijd gestoken in het spel. Zo hebben (vaak doorgewinterde) spelers, van wie de helft zich heeft geregistreerd bij een online dataverzamelingssysteem, gemiddeld I30 uur in het spel gestoken. ${ }^{33}$ AM E R ICA's AR MY bereikt dus met een relatief klein budget een groot deel van zijn doelgroep, jongens tussen de 16 en 24 jaar.

De diverse mogelijkheden om de software achter AMERICA's ARMY aan te passen maakt het spel een ideaal testobject voor verschillende Amerikaanse overheidsdiensten. De wetenschappelijke defensietak die het ontwikkelingsteam achter AMERICA'S ARMY ondersteunt, het MOVES instituut, geeft aan dat AMERICA'S ARMY van één van de vele rekruteringsmiddelen is veranderd in een 
belangrijk (start)punt voor het gebruik en de ontwikkeling van defensiesimulaties:

'Before AM E R ICA's ARMY, DoD [Department of Defense] was "kind of" interested in using games for training and experimentation. With AMERICA's ARMY produced inside the DoD tent, now nearly every group that requires training, experimentation, and analysis systems is thinking of building their next-generation system with a game face. ${ }^{34}$

In deze zin neemt AM E R ICA's ARMY een voortrekkersrol in binnen de militaire informatiemaatschappij:

'Computer-based models of war, work and learning can promote military values, even when they apparently encourage the operator to "think". In all those ways, we are presently heading towards a military information society, which encompasses much more of our lives than we would like to acknowledge. ${ }^{35}$

AMERICA'S ARMY bouwt verder op bestaande conventies binnen het F PS-genre en de F S P-game cultuur en dringt haast ongemerkt de populaire cultuur binnen. Alles wijst erop dat AMERICA'S ARMY geen incident is maar een eerste stap in het ontwikkelen van multidimensionale simulaties, dienend als vermaak, maar ook in te zetten voor training, rekrutering dan wel marketingdoeleinden, educatie en op verschillende niveaus als testmiddel.

\section{Het militaire entertainmentcomplex}

De eerste stappen die geleid hebben tot de uiteindelijke ontwikkeling en het huidige gebruik van AMERICA's ARMY zijn terug te voeren naar het begin van de jaren tachtig en de opkomst van bruikbare simulatietechnieken. Aan het eind van de Koude Oorlog veranderde de organisatiestructuur van de Amerikaanse strijdkrachten ingrijpend, iets wat zijn weerslag had op het gebruik en het inzetten van nieuwe technologieën en investeren in research \& development, met name in de modeling and simulation onderzoekstak van het Amerikaanse leger. De stijgende kosten, nodig voor het organiseren van live-fire training, zorgden ervoor dat andere manieren werden gezocht om soldaten op toekomstige conflicten voor te bereiden. Door de opkomst van steeds geavanceerder en goedkoper wordende informatie- en communicatietechnologieën kreeg het Amerikaanse militaire apparaat toegang tot een hardware en software infrastructuur die het mogelijk maakte om met een fractie van de oorspronkelijke kosten wapensystemen, maar ook hele veldslagen te simuleren. Speciaal gefabriceerde en dus dure stand-alone simulatoren, gebruikt in de jaren tachtig, werden hierdoor over- 
bodig. Grote investeringen in ontwikkeling op het gebied van simulatietechnologie - oorspronkelijk een militair onderzoeksgebied - zijn de laatste decennia dan ook met name gedaan door de groeiende commerciële computerspellenindustrie. Zo bedroegen de ontwikkelingskosten voor de spelconsole van Microsoft, de хвох, twee miljard dollar. Aanzienlijk meer dan het I.6 miljard dollar tellende science and technology-budget van de Amerikaanse defensie. ${ }^{36}$

In 1994 werd de Federal Acquisition Streamlining Act aangenomen, een wet die erop gericht was om eerst naar zogenaamde Commercial of the Shelve (сотs) alternatieven te kijken voordat er aangepast en dus duur materiaal geproduceerd werd door speciale defense contractors. Later in 1997 werd door de us National Research Council (NRC) een rapport uitgevaardigd dat een gezamenlijke onderzoeksagenda toonde om de ontwikkelingen in simulatietechniek binnen zowel de defensie-industrie als de entertainmentindustrie met elkaar in contact te brengen. ${ }^{37}$ Deze twee beslissingen resulteerden in een verdere convergentie van commerciële en overheidssimulatietechnieken en de opkomst van het militaire entertainmentcomplex. ${ }^{38}$

De vraag of het Amerikaanse leger simulatietechniek voor training inzet omdat het mogelijk is of omdat het daadwerkelijk tot betere resultaten leidt, is een nader onderzoek waard. Michael Macedonia is in ieder geval uitgesproken over de kracht van trainingssimulaties:

'The result has been nothing less than remarkable. Low u.s. casualties in Desert Storm, the Balkans, and now Afghanistan stem in large part from the growing use of training simulators, according to a task force of the U.s. Defense Science Board, whose 35 civilian members advise the Secretary of Defense on matters of military R\&D. ${ }^{39}$

Dat de Amerikaanse defensie zich hierbij wendt tot commerciële spel- en simulatie-ontwikkelaars is evident. Zij beschikken immers over de technologische kennis om grootschalige en technologisch hoogstaande simulaties te fabriceren tegen relatief lage kosten. Tegelijkertijd is deze industrie in staat om simulaties te maken met spelelementen, zodat voor het leger gemaakte simulaties enerzijds een aantrekkelijke vorm van training worden en aan de andere kant kunnen dienen als vermaak. Hoe dicht de ontwikkelingen van militaire simulaties en commerciële oorlogsspellen bij elkaar kunnen liggen bewijst het strategiespel full SPeCtrum War rior (Pandemic Studios, 2004: xbox). De ontwikkeling van dit spel begon als trainingssimulator voor het Amerikaanse leger, maar tegelijkertijd werd de legerversie aangepast voor commercieel gebruik. De onderliggende techniek en de algehele gameplay van beide versies komen overeen. Spelers hebben zelfs toegang tot de legerversie, aanwezig op de DVD van het spel. Burgers kunnen bijgevolg direct gebruikmaken van een trainingssimulator van het Amerikaanse leger. 
Screenshot MEDAL OF HONOR (2015 Inc, 2002)

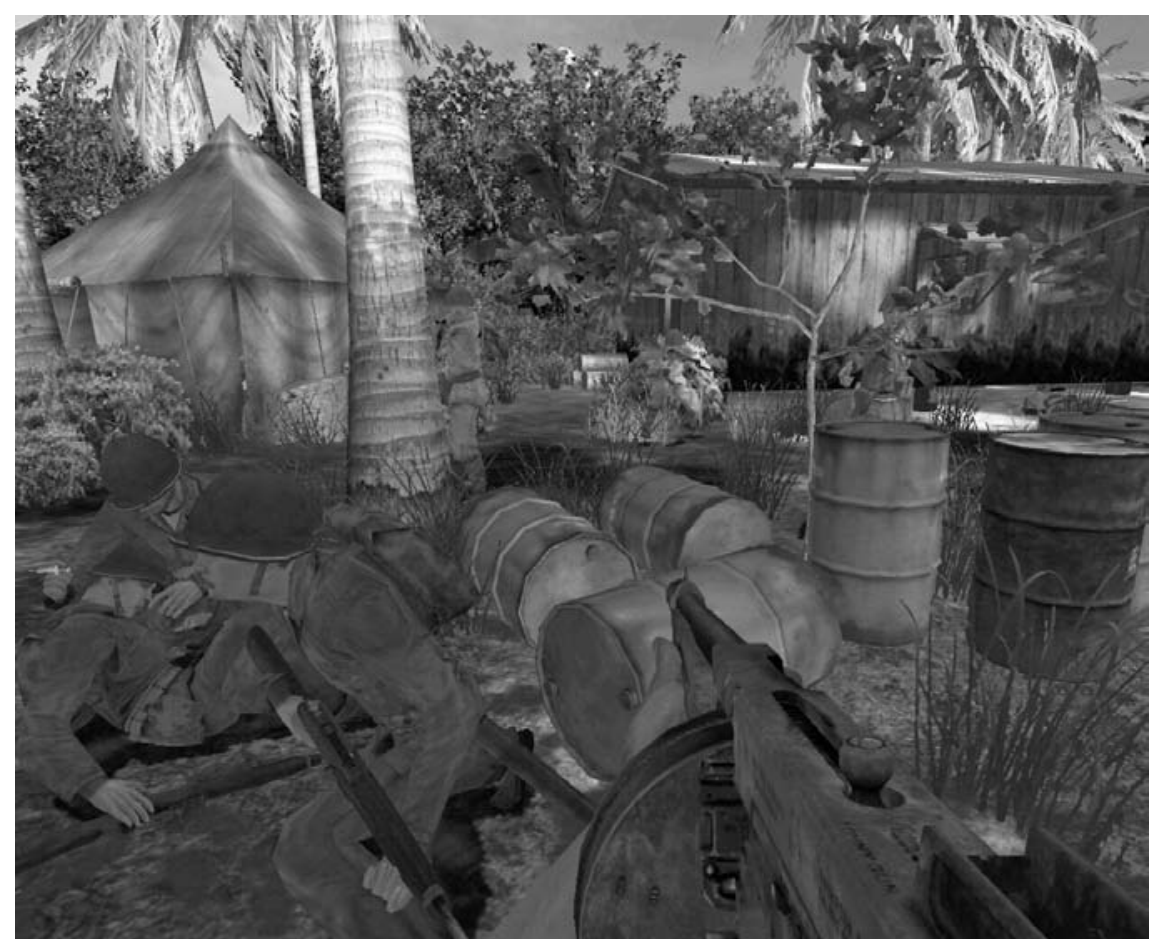

De consequentie van het geloof in simulatietechniek is dat er binnen het Amerikaanse leger een groot aantal simulaties beschikbaar is om soldaten te trainen op verschillende niveaus. Variërend van simpele lasertechniek om het schieten met geweren te oefenen tot grootschalige virtuele omgevingen, zoals het in ontwikkeling zijnde AwE (Asymmetric Warfare Environment), geproduceerd door een commerciële gamestudio..$^{40}$ Voor het trainen van vaardigheden die direct gerelateerd zijn aan computerapplicaties lijkt het gebruik van simulaties ideaal. Zo wijst een studie van de Amerikaanse Marine uit dat het thuisgebruik van de commerciële simulatie MICROSOFT FLIGHT SIMULATOR door piloten in training tot significant betere resultaten in oefeningen leidt. ${ }^{4 \mathrm{I}}$ De grenzen tussen simulatie, training en realiteit vervagen bij het gebruik van een Predator Unmanned Aerial Vehicle. Bij dit op afstand bestuurbare vliegtuigje gebruikt de piloot tijdens een trainingssimulatie dezelfde hardware en software voor de bediening als bij een daadwerkelijke operatie..$^{22}$

Vanwege de nadruk op infanteriegevechtssimulaties en het technisch modificeerbare karakter van de onderliggende techniek zijn ook FPs-games een populair middel om met name teamwork en 'repetitive decision making' te trainen. ${ }^{43}$ Doom 2 (id Software, I994) werd al vóór het rapport van de National Research Council opgemerkt door het Amerikaanse Korps Mariniers en in I995 aangepast om te dienen als trainingsmiddel. MARIN E DOO M werd de eerste F PS die door het Amerikaanse leger werd gebruikt om soldaten te trainen. Later zou- 
den zowel meer commerciële als aangepaste F ps-games volgen. Zo is de commerciële FPS OPERATION FLASH POINT omgevormd door Bohemia Interactive tot de trainingssimulatie IVBS, maar ook commerciële spellen als CoUNTERSTRIKE En MEDAL OF HONOUR worden door verschillende onderdelen binnen het Amerikaanse leger gebruikt. ${ }^{44} \mathrm{Het}$ is aannemelijk dat AM E RICA's AR MY een deel van deze spellen heeft of zal vervangen.

Het gebruik van commerciële games als trainingsmiddel heeft een grote vlucht genomen en geeft een idee van het geloof van het Amerikaanse leger in dergelijke simulaties en de bereidheid om deze in te zetten als voorbereiding op de echte strijd. Moderne wapens en de spellen die deze wapens simuleren hebben steeds vaker dezelfde interface, een computerscherm, een toetsenbord en allerlei aangepaste bedieningspanelen. Deze vervagende grens heeft als gevolg dat relatief goedkope simulatietechnieken uit de entertainmentindustrie een waardevol alternatief worden, dat aansluit bij de computervaardigheden van een nieuwe generatie soldaten. Als AMERICA'S ARMY iets duidelijk maakt is het dat de scheidslijn tussen het inzetten van militaire games als oefening enerzijds en als vermaak anderzijds, aan het verdwijnen is.

\section{Dit is echte oorlog!}

Het massaal zich toe-eigenen van militaire simulaties, maar ook het representeren van de gruwelijkheid van oorlog op het televisie- of computerscherm, heeft gevolgen voor het denken over deze vormen van vermaak. De wisselwerking tussen zichts- en perceptietechnologieën en de ontwikkeling van oorlogstuig in de twintigste eeuw heeft geresulteerd in een de-realisatie van oorlog, zo betoogt Paul Virilio in zijn essay War and Cinema: The logistics of perception. Het slagveld is altijd een veld van perceptie geweest waarbij het zien van de tegenstander gelijk staat aan het in staat zijn tot het vernietigen van deze tegenstander. 'Winning is keeping the target in constant sight', aldus Virilio. ${ }^{45}$ Deze perceptuele karakteristiek van moderne oorlogsvoering heeft tevens zijn weerslag in de, soms simplistische, simulaties van interpersoonlijke gevechten in F Ps-games. Spelers van deze spellen zullen beamen dat gezien worden in een F P s zoveel betekent als 'doden of gedood worden', het zien van een tegenstander in een online gevecht heeft een onvermijdelijke virtuele dood van één van de spelers tot gevolg. Terugtrekken of vluchten is in de chaotische wereld van de F Ps een luxe die spelers zich zelden kunnen permitteren. Het proces van zien heeft ook in de hedendaagse FPs-spelcultuur zijn onschuld verloren.

Virilio betoogt dat het videosignaal het klassieke radiosignaal vervangt en een oorlog van beelden en geluiden de oorlog van objecten (projectielen en raketten) zal vervangen ${ }^{46}$ De Eerste Golfoorlog van I99I veranderde door de surreële verslaglegging tijdens de nooit stoppende oorlogsrapportages op televisie, in een conflict dat slechts heeft plaatsgevonden op televisie in de besloten sfeer 
van de huiskamer. Het slepende conflict in Vietnam was de eerste oorlog waarbij oorlogsbeelden direct de huiskamer binnenkwamen, wat invloed had op de publieke opinie ten opzichte van deze oorlog. ${ }^{47}$ De Amerikaanse politiek en het leger hebben verschillende lessen geleerd van de Vietnamoorlog, lessen die tijdens de eerste Golfoorlog in de praktijk werden gebracht. De informatiestroom en de pers werden zorgvuldig beheerst; zo was er tijdens de troepenopbouw in I99I in de Amerikaanse media slechts aandacht voor de logistieke achtergrond van de grootste Amerikaanse militaire operatie sinds Vietnam. ${ }^{48}$ De Golfoorlog werd de perfecte representatie van een klinische technowar, een beeld van een oorlog die de Vietnamoorlog had moeten zijn. ${ }^{49}$

Wanneer oorlog, zo betoogt Jean Baudrillard in zijn essay The Gulf War did not take place, verworden is tot informatie, houdt het op een reëel conflict te zijn en wordt het een virtuele gebeurtenis. Kijkers hebben behoefte aan media, als ware het drugs die voorzien in de hallucinatie van geweld. 'We have a pressing need for simulation, even that of war. ${ }^{50}$ Frs-games zijn de simulaties die de honger naar het veilig beleven van oorlog kunnen stillen. William Uricchio vat deze ontwikkeling samen als de samenkomst van perceptie en actie:

'Curiously, indeed almost perversely, the closer we come to the merge of perception and action, the more the systems and discourses that we employ look like the games we play. But in an era where Hollywood films inspire the largest defence expenditures to date, and where videogames anticipate our most sophisticated weapons systems, perhaps this should come as no great surprise. ${ }^{51}$

Hoe computerspellen geplaatst worden binnen het journalistieke discours ten tijde van de Tweede Golfoorlog werpt een interessant licht op de verschillende (voor)oordelen die er zijn over games en simulaties. In Mia Consalvo's studie naar het gebruik van verwijzingen naar videogames binnen het nieuwsdiscours is gereconstrueerd hoe videogames binnen de discours van populaire media functioneren..$^{52}$ Aan de hand van een analyse van transcripten van Amerikaanse nieuwsprogramma's is een tegenstrijdigheid waar te nemen wat betreft het refereren aan computerspellen en oorlog. Het Amerikaanse leger neemt simulaties en militaire games uitermate serieus, wat blijkt uit het gebruik van een groot aantal (commerciële) games. In het journalistieke discours daarentegen worden diezelfde commerciële games afgeschilderd als vormen van triviaal vermaak. Consalvo wijt dit aan een gebrek aan kennis van het medium. In journaals worden computerspellen gebruikt om de focus te richten op goed ontwikkelde technologieën. Zo is er bijvoorbeeld een parallel tussen militaire technologie en game-technologie, onder andere door het gebruik van live satellietbeelden en militaire karteringstechnologie. Een tweede trend die zij waarneemt is het refereren aan het min of meer afwezig zijn van menselijk lijden dan wel de onrealistische en niet-serieuze representatie van de dood, iets wat de volgende waar- 
schuwing uitlokte bij een nieuwslezer: 'Remember, this is a real war - not a videogame'. De representatie van games binnen het journalistieke discours zegt veel over de status van games als cultureel artefact. In de F PS KU MA|WAR (Kuma Reality Games, 2004) vervaagt de scheidslijn tussen echte en virtuele oorlog en dienen de gebeurtenissen in het nieuws als inspiratie en achtergrond voor een nieuw spel. Een spel dat voor de representatie en simulatie van oorlogshandelingen leent van de verbeeldingsprincipes binnen televisiejournaals.

KUMA\WAR: real war?

De Tweede Golfoorlog had in tegenstelling tot de Eerste een ander medium als referent, namelijk computerspellen in plaats van televisie. 'If Kuma has its way, the next revolution won't just be televised, it'll also be digitized. ${ }^{53}$ Waar de representatie van recente militaire conflicten, de berichtgeving omtrent deze conflicten en games op een merkwaardige manier in elkaar overvloeien, is de F PS-game KUMA|WAR. In dit spel is het mogelijk om in singleplayer modus of online in multiplayer modus missies (na) te spelen die gebaseerd zijn op actuele gebeurtenissen, gewapende conflicten uit het wereldnieuws. KumA|WAR past uitstekend in het FPS-genre en neemt een aantal conventies van de tactical shooter over, zoals het vechten in twee teams en de nadruk op het uitvechten van een gewapend conflict met een reeks van moderne wapens. Hoewel er meer spellen zijn die moderne conflicten simuleren en representeren, maakt KU MA|WAR een expliciete link met gevechtshandelingen binnen Operatie Iraqi Freedom. De eerste missie van het spel, genaamd Uday and Qusay's Last Stand, plaatst de speler in de schoenen van een Amerikaanse soldaat die de opdracht heeft de zonen van Saddam Hoessein gevangen te nemen. De echte Amerikaanse operatie vond plaats in juli 2003. In een rapport naar aanleiding van deze actie deed luitenantgeneraal Ricardo Sanchez de volgende uitspraak over het verloop van dit gevecht:

'They [Saddam's zonen] died in a fierce gun battle. They resisted the detention and the efforts of the coalition forces to go in there and apprehend them, and they were killed in the ensuing gunfight and the attacks that we conducted on the residence. ${ }^{54}$

De missie in KUMA|WAR, uitgebracht in februari 2004, bestaat uit twee delen. In het eerste deel is de opdracht het afsluiten van het gebied rondom het huis waar de Hoessein-broers zich bevinden. In het tweede deel kan de speler de broers doden. De mogelijkheid om de broers levend gevangen te nemen wordt door de makers van het spel uitgesloten. Voordat spelers aan de missie beginnen krijgen zij toegang tot een schat aan informatie om zich zo op de missie voor te bereiden. Zo is er informatie over de tegenstanders, de te gebruiken wapens, tactische tips om de aanval te plannen, satellietfoto's en een overzicht van de 
chronologische gebeurtenissen tot het moment waarop het spel begint. Daarnaast is er beeldmateriaal over de missie beschikbaar die de grens tussen realiteit en simulatie doet vervagen. De KU MA |WAR nieuwslezer brieft de gamer voor het begin van de missie door middel van een kort filmpje met authentieke beelden. Deze inleidende filmpjes en de website van KU MA|WAR vertonen aanzienlijke overeenkomsten met de interface van (Amerikaanse) nieuwszenders, zoals CNN. De accuraatheid van het spel wordt nog eens benadrukt door de spelontwikkelaars. Zo is er een 'ervaren' documentairemaker en news producer in dienst, evenals een militaire consultant, een gepensioneerde generaal-majoor die voorheen werkzaam was bij de Amerikaanse Mariniers.

Het spel wordt geproduceerd door de commerciële ontwikkelingsstudio Kuma Reality Games die zijn hoofdkwartier in New York heeft. De makers distribueren het spel via internet en gamers kunnen voor 9.99 dollar per maand een abonnement nemen. 'We have developed an innovative new entertainment genre combining the best of reality television with high-quality action gaming', aldus K. Halper, directeur van Kuma Reality Games. ${ }^{55}$ Op het juridische gedeelte van de website staat een paradoxale tekst die de relatie tussen simulatie en nieuws duidelijk maakt:

'Kuma games are works of fiction. Any Kuma game that is based on realworld events is only representational and not an accurate depiction of realworld events. You should not rely on the accuracy of any Kuma game for any purpose, and under no circumstances should you seek to imitate any game experience in real life. ${ }^{, 56}$

In de herfst van 2004 komt er een CD-Rom versie van het spel beschikbaar onder de naam KUMA|WAR: THE WAR ON TERROR. De belangrijkste gevechtshandelingen van de Tweede Golfoorlog kunnen tot in de oneindigheid overgedaan worden door gamers. Waar in reclameslogans het objectieve imago van games als simulaties benadrukt en het spel aangeprezen wordt als de mogelijkheid om oorlog na te spelen, daar wijst de waarschuwing op de website van Kuma Reality Games nog eens op het subjectieve karakter van de representaties en simulaties van dit conflict.

\section{Conclusie}

Was de D-Day landing in Spielbergs film SAVING PRIVATE RYAN (I998) een één uur durende representatie van een gruwelijke slachting, simulaties van deze en vergelijkbare landingen zijn terug te vinden in een grote reeks F Ps-spellen als MEDAL OF HONOUR: ALLIED ASSAULT, BATTLEFIELD I942 en RETURN TO CASTLE WOLFENSTEIN. Door vele gamers worden ze urenlang gespeeld in een immersieve ervaring. Hetzelfde geldt voor de ervaringen van The War on Terror. 
Hoewel de beelden van het conflict uit het nieuws verdwijnen, aan de ene kant doordat het simpelweg geen nieuws meer is of omdat het conflict verplaatst is naar een ander deel van de wereld, wordt het conflict haast tot in het oneindige gesimuleerd in talloze online F Ps-sessies. De Eerste Golfoorlog, Desert Storm, was een oorlog die voor velen gerepresenteerd werd door de televisie. Dat zorgde voor een hyperreëel conflict door de klinische representatie van menselijk lijden en een nadruk op de gemedieerde dood. Het eerste grote conflict in de 2re eeuw, operatie Iraqi Freedom, zet deze trend voort maar is tevens een gesimuleerd conflict dat immer voortduurt en uitgevochten wordt in de speelkamers van jonge mensen. Waar de televisie de Eerste Golfoorlog verbeeldde door een geselecteerde representatie van beeld en geluid, daar wordt de Tweede Golfoorlog gesimuleerd door games, met een configuratieve ervaring tot gevolg.

Een groot aantal gamers heeft een fascinatie voor het 'ervaren' van (recente) militaire geschiedenis, mede vanwege het speculatieve karakter van simulaties die reflectie op verschillende versies van die geschiedenis mogelijk maken. ${ }^{57}$ Hoe zou het zijn om Irakezen te verslaan zonder tanks? Hoe is het om daadwerkelijk een oorlog uit te vechten net als op televisie? Hoe is het om zelf bommen te richten en te gooien op een huizenblok of een rij tanks? Digitale simulaties en F P S-spellen bieden gamers de mogelijkheid om elk denkbaar conflict uit te vechten, alleen, met vrienden of online met volstrekt onbekenden. De verhouding tussen de simulatie van oorlog in games en de representatie van oorlog in televisiejournaals verandert doordat gamers in staat zijn om een conflict van enkele maanden oud op de PC of spelconsole na te spelen en nogmaals te ervaren. Een spel als KU MA |WAR verkort deze tijd aanzienlijk en maakt het mogelijk om haast real-time vanuit een eerste persoonsperspectief een oorlogsmissie na te spelen. Het proberen om leden van de familie Hoessein gevangen te nemen is verworden tot een spel. Crogan komt met een welkome waarschuwing:

'In marking out the exclusion operative in the informational experience of events, the First-Person Shooter reminds us of a powerful technocultural desire to encounter the future in the form of anticipated, controllable contingencies. At the same time, it cautions us about playing that game, even if it is the only one in town. ${ }^{58}$

FPs-spellen benadrukken en verkopen zichzelf steeds meer als simulaties, daarbij (on)bewust het aura van objectiviteit in digitale simulaties benadrukkend. De geschiedenis van de First-Person Shooter laat zien dat de zucht naar verdere technische innovaties het genre vooruit stuwt. Door gamers wordt van F Ps-spellen verwacht dat zij ook daadwerkelijk realistischer overkomen, door een waarheidsgetrouwe audiovisuele representatie van de werkelijkheid maar ook door het aanbieden van immersieve virtuele werelden waar alles in dienst staat van het voeren van 'echte' of in ieder geval zo echt mogelijk lijkende oorlog. Zo worden F PS-games minder lineair, is het mogelijk om in nog grotere gebieden te spelen 


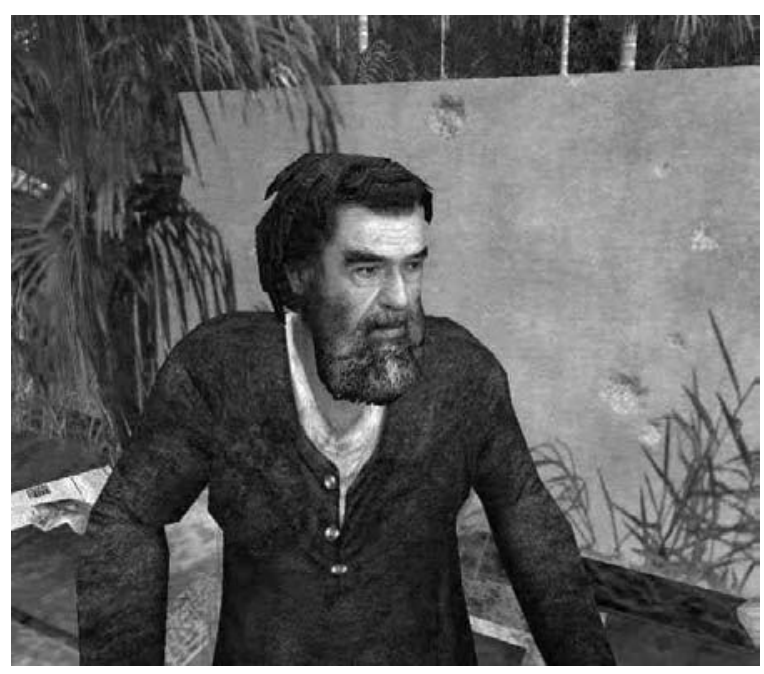

Ingame screenshot uit de FPS KU MA|WAR in een missie waarin Saddam Hoessein gevangen genomen kan worden (Kuma Reality Games, 2004) en met nog meer mensen tegelijk online te zijn en dit alles in een bijna fotorealistische omgeving. Op het oog simpele zaken als de wetten van de zwaartekracht en vernietigbare oppervlakten worden gedetailleerd geprogrammeerd om de werkelijkheid in al zijn complexiteit te simuleren. Het genre van de tactical F PS gaat welhaast nog verder door het modelleren van realistisch wapentuig. Daarin wordt zelfs de baan van kogels real-time berekend en wordt de rekenkracht van de software-engine ingezet om gamers zoveel mogelijk tactieken te kunnen laten gebruiken. Tactieken die voorheen voorbehouden waren aan soldaten binnen het Amerikaanse leger, zo meent kapitein Amerine:

'You could tell in some cases you have significantly younger people, probably junior high or so (...) they'd be saying things back and forth that indicated to me that this was sort of an extension of guys who grew up on Rainbow Six and other first-person shooters (...) the techniques they would use just by figuring it out would end up being very similar to what we would do in real life. ${ }^{59}$

Het Amerikaanse leger profiteert gretig van deze positieve attitude van gamers ten opzichte van alles wat met de representatie van wapens en (recente) oorlogsvoering te maken heeft. Direct door positieve aandacht en het kunnen werven van rekruten via diverse spellen en de FPS AMERICA'S ARMY in het bijzonder. Indirect profiteert het leger van de enorme investeringen die de commerciële game-industrie doet om gamers te voorzien van nog betere simulatietechnieken. Het gevolg is een verregaande samenwerking tussen het Amerikaanse leger en de commerciële computerspellenindustrie, wat zijn weerslag heeft op de representatie van oorlog binnen de populaire cultuur. Het succesvolle militaire entertainment-complex heeft een militaire entertainment-cultuur tot gevolg. Au verwoordt dit als volgt:

'In that regard, America's Army and Delta Force: Black Hawk Down are the "Why We Fight" for the digital generation. Though not explicitly doctrinaire in an ideological sense, by showing the very young how we fight, applying the moral application of lethal force on behalf of liberal values, these games create the wartime culture that is so desperately needed now. ${ }^{, 60}$ 
Het meest succesvolle rekruteringsmiddel voor het Amerikaanse leger, het F P S-spel AM E R ICA'S AR MY, lijkt een voorbode van wat mogelijk is met commerciële simulatietechnieken. Dezelfde spellen die ingezet worden voor de training van soldaten, om nieuwe wapens en tactieken te testen en om reclameboodschappen over te brengen, worden gretig door gamers aangewend ter vermaak. De toekomst voor AM E RICA's ARMY en militaire game(r)s ziet er rooskleurig uit.

I 'So the computer game epitomises the field of computer culture in a sense' volgens Espen Aarseth in: P. Crogan, 'Games, Simulation \& Serious Fun: An Interview With Espen Aarseth', in: Journal of media arts culture, jg.I nr.I, 2004, http://scan.net.au/scan/journal/display_article. php?recordid $=20$.

2 B. Kester, H. Wijfjes, 'Media en oorlog', in: Tijdschrift voor Mediageschiedenis, jg. 2 nr. 2, I999, p. 4.

3 Idem, p. I3.

4 P. Crogan, 'The Experience of information in Computer games', 2003; http://www.hypertext.rmit.edu.au/dac/papers/Crogan.pdf.

5 Gonzalo Frasca zet deze gedachtelijn uiteen in zijn Master thesis. Hij definieert simulaties als een: 'representation of processes that mimic a system by the behavior of another, even if its source system is not real.' G. Frasca, 'Videogames of the Oppressed - Videogames as a Means for Critical Thinking and Debate.' Master Thesis aan de Georgia Institute of Technology, 200I, http://www. ludology.org/articles/thesis/.

6 Gonzalo Frasca voegt hieraan toe dat 'simulation and representation are two ways of dealing with reality. Until now, both have coexisted in our culture, but representation, along with narrative, have been dominant, mainly because complex simulations require a level of technical sophistication that is impossible without a computer.' G. Frasca, 'Simulation IoI: Simulation versus Representation', in: Ludology.org, 200I; http://www.ludology.org/articles/sims/simulationior.html.

7 C. Crawford, 'Serious Games: Improving Public Policy through Game-based Learning and Simulation', 2003, http://www.seriousgames.org/images/Seriousgamescrawfordfinal.pdf.

8 P. Virilio, War and cinema: the logistics of perception, (P. Camiller, translation), London/New York I989, p. 47.

9 Delta force (NovaLogic, 1998) is een tactical fps gebaseerd op de Amerikaanse Special Forces. J. Au, 'Weapons of mass distraction', in: Salon.com, 2002; http://www.salon.com/tech/ feature/2002/10/04/why_we_fight.

Io Crawford 'Serious Games'.

II D. Kushner, Masters of Doom: How two guys created an empire and transformed pop culture, New York 2003 .

I2 J. Au, 'Masters of “Doom”' in: Salon.com, 2003; www.salon.com/tech/feature/2003/ 05/05/doom/.

I3 K. Salen \& E. Zimmerman, Rules of play: game design fundamentals. Cambridge, 2004. Katie Salen en Eric Zimmerman gebruiken de volgende definitie voor games: 'A game is a system in which players engage in an artificial conflict, defined by rules, that results in a quantifiable outcome.' (p. 80).

I4 Deathmatch is een spelvorm waarin spelers het tegen elkaar opnemen maar zich niet verenigen in teams. Deze spelvorm wordt ook wel Free For All genoemd en is kenmerkend voor de eerste multiplayer F P s-games. Het opnieuw tot leven komen binnen een spel wordt respawning genoemd. 
I5 First-Person Shooter games bestaan doorgaans uit verschillende maps. Deze afgebakende speelvelden worden binnen een ontwikkelingsteam geproduceerd door gespecialiseerde leveldesigners.

I6 De opkomst en geschiedenis van verschillende game communities mede door online FPSgames is beschreven door B. King \& J. Borland, Dungeons and Dreamers: The Rise of Computer Game Culture from Geek to Chic, San Francisco 2003. Netwerktechnologie is uiteraard niet (langer) voorbehouden aan FPs-games, met name online Role Playing Games (RPGS) trekken dagelijks honderdduizenden mensen.

I7 H. Jenkins, 'Interactive Audiences? The collective intelligence of media fans', in: D. Harries (ed.), The New Media Book, London 2002.

I8 Zie voor een uitgebreide analyse van de huidige trends in de First-Person Shooter mod cultuur en de implicaties van deze cultuur voor de relatie tussen game ontwikkelaars, uitgevers en games: D.B. Nieborg, 'Who put the mod in commodification? - A descriptive analysis of the First Person Shooter mod culture', 2004; http://www.gamespace.nl/research.htm.

I9 J.C. Herz, M. Macedonia, 'Computer Games and the Military: Two Views', in: Defense Horizons, hr. II, 2002.

20 Om aan te geven wat de maatschappelijke waarde is van COUNTER-STRI KE: elk moment van de dag zijn er tussen de 60.000 en 80.000 gamers online COUNTER-STRIKE aan het spelen. Zie: http://archive.gamespy.com/stats/ voor actuele statistieken van een groot deel van de online FPsgames.

2I M. Bowden, Black Hawk Down: A Story of Modern War, New York I999.

22 Persoonlijke communicatie met uitgever Afkarmedia, d.d. I7 Juli 2004. 'UNDERASH was addressed to Arab youths whom are already familiar with conflict chronicles, while UN DERSI EG E is addressed to youths all over the world'. Van UN DERASH zijn meer dan 300.000 eenheden verkocht. Door de uitgever van UN DERASH wordt SPECIAL FORCE omschreven als 'political propaganda'.

23 M. Wiltenburg, 'Sophisticated Recruiting', in: CSMonitor.com, 3 April 2003; http://www. csmonitor.com/2003/0403/pi4soI-stct.htm.

24 W. Uricchio, 'Media and war... beyond propaganda', in: Tijdschrift voor Mediageschiedenis, jg. 2 nr. 2, I999, p. I63.

25 B. Sterling, 'War is Virtual Hell' in: Wired.com, I993; http://www.wired.com/wired/ archive/I.oI/virthell_pr.html.

26 De versie die voor deze analyse gebruikt is, is AM ERICA'S ARMY: Special Forces Downrange (us Army, 2004). Deze versie (2.I) is uitgegeven op I juni 2004. Alle eerdere versies zijn tevens gespeeld en worden meegenomen in deze analyse. Daar AM E R ICA's AR M Y een spel is in constante ontwikkeling, zullen sommige aspecten niet altijd consistent zijn naarmate de ontwikkeling van het spel vordert. De ontwikkeling van zowel het spel als de community is stormachtig geweest en is een verdere bestudering zeker waard. Zie ook http://www.americasarmy.com/.

27 Deze vier dimensies zijn voor het eerst genoemd in S. van der Graaf en D. B. Nieborg, 'Together We Brand: America's Army' in: M. Copier, J. Raessens (red.), Level Up: Digital Games Research Conference, Utrecht 2003. De vier dimensies zijn verder uitgewerkt in het artikel van D.B. Nieborg, 'America's Army: more than a game?' in: Bridging the Gap: Transforming Knowledge into Action through Gaming and Simulation. München 2004.

28 D. Becker, 'Army gunning for game players', in: News.com, 2004; http://news.com.com/ 2100-I043-52II682.html.

29 Frasca, 'Videogames of the Oppressed'. p. 58.

30 N. Tran, 'America's Army version 2.0 Training Manual: Army Game Project', 2003; http://www.americasarmy.com/support/gamemanual.php. p. 36, p. 76, p. 94.

3I Volgens de directeur van het Army Game Project is America's ARmy: 'The Army's most effective medium for reaching young Americans. Indeed, the game engendered positive awareness of Soldiering among twenty-nine percent of young Americans age I6 to 24. Importantly, the game achieved these results at an expenditure of about one-third of one percent of the Army's total marketing budget.' M. Davis (ed.), America's Army Pc Game Vision and Realization, San Francisco 2004 . 
32 Zie http://archive.gamespy.com/stats/ en http://www.americasarmy.com/ voor actuele data.

33 Zie http://aaotracker.4players.de/trackerstats.php voor actuele statistieken. Hoewel deze statistieken niet representatief zijn geven ze een goed beeld van trends en gemiddelden.

34 M. Zyda, 'Does the Future of Modeling and Simulation have a Game Face?', in: M. Davis (ed.), America's Army Pc Game Vision and Realization, San Francisco 2004, p. 23.

35 Patrick Crogan definieert een militaire informatiemaatschappij als 'one in which the military plays a pervasive role via the spread of computer culture and the resultant dissemination of a military-inspired cybernetic paradigm of the world into all aspects of existence.' Crogan. 'The Experience of information in Computer games', p. I59.

36 Herz \& Macedonia, 'Computer Games and the Military: Two Views'.

37 M. Zyda and J. Sheehan (eds.) Modeling and Simulation: Linking Entertainment \& Defense, Washington 1997. Het Army Game Project en dus AmericA's ARmy, geïnitieerd in I999, is een direct resultaat van dit rapport.

38 T. Lenoir, 'All But War Is Simulation: The Military Entertainment Complex', in: Configurations, jg. 8, 2000, p. 238-335.

39 M. Macedonia, 'Games Soldiers Play', in: IEEESpectrum Online, 2004; http://www. spectrum.ieee.org/W E B о LIY /publicfeature/maro2/mili.html. (R\&D = Research and Development).

40 L. Gonzalez, 'Spot On: The us Army's There-based simulation' in: Gamespot.com, 2I April 2004; http://www.gamespot.com/news/2004/04/2I/news_6093860.html.

4I Herz \& Macedonia, 'Computer Games and the Military: Two Views'.

42 Macedonia, 'Games Soldiers Play'.

43 R. Riddel, 'Doom Goes To War', in: Wired.com,I997; http://www.wired.com/wired/ archive/5.04/ff_doom.html.

44 Zie http://www.dodgamecommunity.com voor een overzicht van verschillende games die gebruikt worden door het Amerikaanse leger.

45 Virilio, War and cinema, p. 2.

46 Idem, p. 4.

47 Tijdens de eerste Golfoorlog heeft de Amerikaanse legermacht het zogenaamde pool system ingevoerd. 'The military organized the pool system, however, because they perceived that reporting had been too critical in Vietnam, and they blamed the press for helping erode public support for the war'. D. Kellner, The Persian Gulf TV War, Boulder I992, beschikbaar op http://www.gseis.ucla. edu/faculty/kellner/kellnerhtml.html.

48 'Tv reports centred on desert manoeuvres and the depiction of shiny and powerful new high-tech weapons.' Kellner voegt hieraan toe dat televisie als medium beslissend was in het produceren van die beelden en discourses die de Amerikaanse krijgsmacht promootten na een lange periode waarin de krijgslieden in opspraak waren en aan de zijlijn van de Amerikaanse maatschappij stonden. Kellner, The Persian Gulf TV War.

49 J.W. Gibson, The Perfect War. Technowar in Vietnam, New York 1986.

50 J. Baudrillard, The Gulf War did not take place, Sydney I995, p. 75.

5I Uricchio, 'Media and war... beyond propaganda', p. I68.

52 M. Consalvo, 'It's no videogame: new commentary and the second gulf war', in: Level Up: Digital Games Research Conference, Utrecht 2003.

53 Citaat uit het Computer Games Magazine van December 2003 te vinden op de website van KUMA|WAR; http://www.kumawar.com/about.php.

54 'Lt. Gen. Sanchez Press Briefing on Uday and Qusay Hussein', 22 juli 2003; http://www. dod.mil/transcripts/2003/tr20030722-042I.html.

55 'Kuma: War - Full Client Available now' in: Worthplaying.com, 3I maart 2004; http:// www.worthplaying.com/article.php? sid=I7009.

56 Zie: http://www.kumawar.com/legal/terms.htm.

57 W. Uricchio, 'Simulation, History and Computer Games' in: J. Goldstein \& J. Raessens (eds), Handbook of Computer Game Studies, Cambridge (te verschijnen).

58 Crogan, 'The Experience of information in Computer games', p. 5. 
$59 \mathrm{Au}$, 'Weapons of mass distraction'. James Wagner Au neemt het verhaal over: 'He [kapitein Amerine] found himself up against kids staggering their formations, using smoke to cover their approach, closing on the enemy with fire and manoeuvre, individual movement techniques (г м т) - in short, acquiring through gameplay knowledge that was once available only through military training.'

$60 \mathrm{Au}$, 'Weapons of mass distraction'. 